\title{
Calcium Sulfate Hemihydrate (Bassanite) Crystals in the Wood of the Tamarix Tree
}

\author{
Steve Weiner ${ }^{1, *}$, Iddo Pinkas $^{2}\left(\mathbb{D}\right.$, Anna Kossoy $^{2}$ and Yishai (Isai) Feldman ${ }^{2}$ \\ 1 Department of Structural Biology, Weizmann Institute of Science, Rehovot 76100, Israel \\ 2 Department of Chemical Research Support, Weizmann Institute of Science, Rehovot 76100, Israel; \\ Iddo.Pinkas@weizmann.ac.il (I.P.); anna-eden.kossoy@weizmann.ac.il (A.K.); \\ Isai.Feldman@weizmann.ac.il (Y.F.) \\ * Correspondence: steve.weiner@weizmann.ac.il
}

Citation: Weiner, S.; Pinkas, I.;

Kossoy, A.; Feldman, Y. Calcium Sulfate Hemihydrate (Bassanite) Crystals in the Wood of the Tamarix Tree. Minerals 2021, 11, 289. https://doi.org/10.3390/ $\min 11030289$

Academic Editor: Alejandro B. Rodriguez-Navarro

Received: 7 February 2021

Accepted: 8 March 2021

Published: 11 March 2021

Publisher's Note: MDPI stays neutral with regard to jurisdictional claims in published maps and institutional affiliations.

Copyright: (c) 2021 by the authors. Licensee MDPI, Basel, Switzerland. This article is an open access article distributed under the terms and conditions of the Creative Commons Attribution (CC BY) license (https:/ / creativecommons.org/licenses/by/ $4.0 /)$.

\begin{abstract}
The most abundant mineral produced in the wood and leaves of trees is calcium oxalate monohydrate (whewellite), and after burning the wood the ash obtained is calcite. In the case of the Tamarix sp. tree, the freshly prepared ash is calcium sulfate (anhydrite). The aim of this study is to determine the calcium sulfate mineral phase in the fresh wood of Tamarix aphylla prior to burning. SEM images of the crystals show that they express smooth faces, are about 5-15 microns in their longest dimensions and are located in the ray cells. Fourier transform infrared spectroscopy (FTIR) and Raman microspectroscopy of the crystals in the wood and after extraction, both showed that the crystals are composed of calcium sulfate hemihydrate (bassanite). As elemental analyses of the crystals showed that in addition to calcium and sulfur, around 20 atom percent of the cations are sodium and potassium, we also obtained an X-ray powder diffraction pattern. This pattern excluded the possibility that the crystals are composed of another related mineral, and confirmed that, indeed, the crystals in the T. aphylla wood are composed of calcium sulfate hemihydrate (bassanite).
\end{abstract}

Keywords: biomineralization; plant minerals; biogenic crystals; tamarix; wood; bassanite; calcium sulfate hemihydrate; plaster of paris

\section{Introduction}

Trees produce a variety of different minerals. The most abundant mineral is calcium oxalate monohydrate (whewellite), which is found in the leaves, wood and bark [1,2]. The calcium oxalate crystal druses are composed of several intergrown crystals. They are found most frequently in ray and/or parenchymal cells, and they often express their natural crystal faces [1]. One proven function of some of these crystals in the leaves of Ficus species is to enhance photosynthesis by scattering light into the dark interior of the leaf [3]. Some Ficus leaves also contain deposits of amorphous calcium carbonate (cystoliths), which enhance photosynthesis [3]. Silica is also widely distributed in the leaves, wood and bark of many trees [4]. These deposits are often called phytoliths. The wood and bark of some trees also contains an unusual mineral deposit in which crystalline minerals, probably derived from the soil, are encapsulated in a matrix composed of silica. As opposed to the silica of phytoliths, which is relatively pure, about half of the cations of the matrix of these so-called siliceous aggregates comprises $\mathrm{Al}, \mathrm{K}$ and $\mathrm{Fe}$ [5]. Calcium sulfate deposits have been identified in several plants based on elemental analyses $[2,6,7]$, but plant calcium sulfate is rare [7].

In a study of wood ash from different trees growing in Greece, Tsartsidou et al. noted that the ash of the Tamarix sp. and Juglans regia is composed of anhydrite $\left(\mathrm{CaSO}_{4}\right)$ [8]. This was confirmed for Tamarix aphylla [9]. The ash of most other trees is composed mainly of calcite (Table 7.1 in [10]), which forms at around $430{ }^{\circ} \mathrm{C}$ to $510^{\circ} \mathrm{C}$ when the calcium oxalate monohydrate loses carbon monoxide [11,12]. The unusual Tamarix and Juglans ash raised the question of what is the mineral phase in the wood prior to burning that produced this 
calcium sulfate ash. X-ray microanalysis of T. aphylla tissue showed that it is a calcium sulfate deposit and the authors suggested that the mineral might be gypsum [13]. The aim of this study was to directly determine the identity of the calcium sulfate mineral in the wood of T. aphylla.

Tamarix species (Tamaricaceae) are typical recretohalophytes, namely that they exclude or secrete salt [14]. These shrubs/trees generally grow in semi-arid and arid climatic zones (Figure 1) [15], and are common in the southern arid regions of Israel (Negev Desert). In Israel, Tamarix sp. trees also grow in the north, including on the banks of the Jordan River. The average annual rainfall in the north of Israel close to the Jordan River is about four times greater than in the south (Israel Meteorological Service).

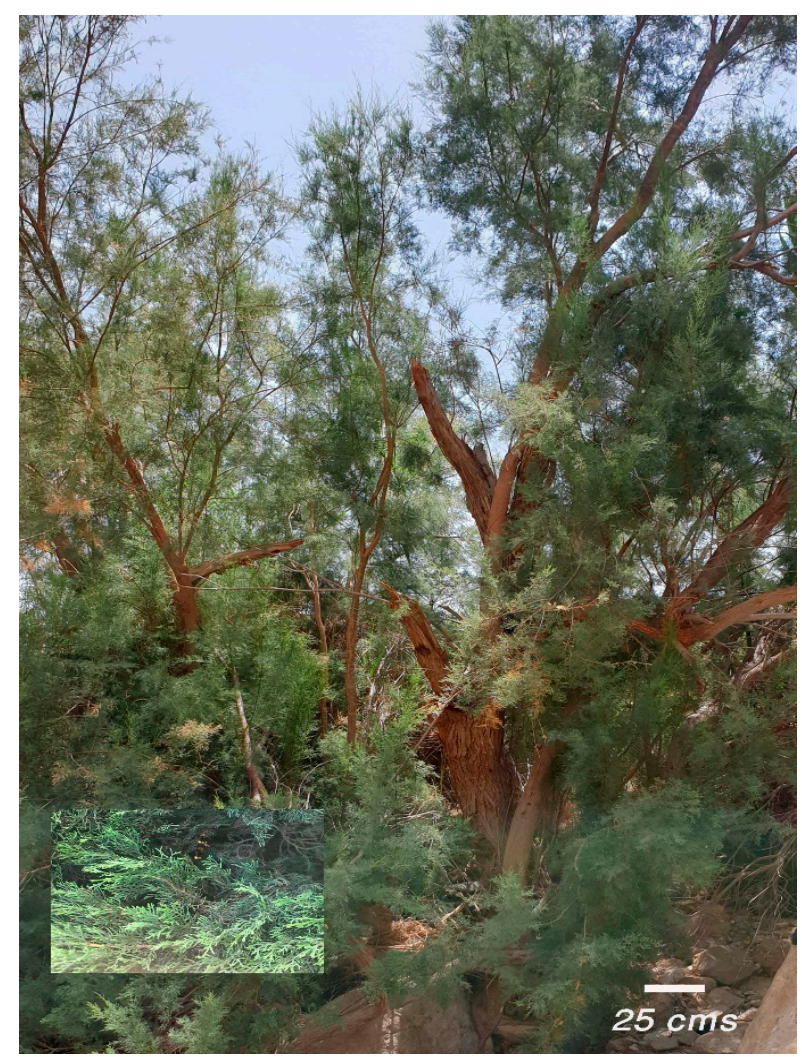

Figure 1. Photograph of a Tamarix tree growing in the Negev Desert, Israel. Inset: higher magnification view of the leaves.

\section{Materials and Methods}

\subsection{Materials}

Wood from thin branches of Tamarix aphylla growing in the usually dry river bed of Nahal Aqev, central Negev (Israel) were analyzed. The species identification was based on the very large diameter of the vessels in the ray cells [16]. Wood from a Tamarix sp. from the banks of the Jordan River in the more humid northern Israel region was also examined. The wood was collected fresh and was stored dry for 25 years. Standards of gypsum, anhydrite and calcium sulfate hemihydrate were purchased from Sigma-Aldrich.

\section{Specimen Preparation}

Several different branches were examined by SEM and they all contained crystals. All the spectroscopic analyses were made on the same branch of T. aphylla from Nahal Aqev in order to be sure that the results are comparable. The branch has a diameter of around $1 \mathrm{~cm}$.

Crystal extraction: About $200 \mathrm{mg}$ of fine saw dust was collected by sawing the branch repeatedly after the bark was removed using a jigsaw with a fine blade. The saw dust was suspended in $10 \mathrm{~mL}$ of $96 \%$ ethanol, vortexed and then sonicated (Branson sonicator 3510, 
Danbury, CT, USA) for one hour. The suspension was then passed through a 21-micron nylon mesh gauze (Sinun Tech, Barkan, Israel) and the filtrate was collected and allowed to stand for $5 \mathrm{~min}$. The pellet was resuspended in $10 \mathrm{~mL} 96 \%$ ethanol and passed through the gauze a second time. After $5 \mathrm{~min}$, the supernatant was removed. A drop of the pellet was dried on a small round microscope cover slip for SEM/EDS analysis and another drop was dried on a microscope slide, for Raman analysis. The remaining pellet was dried and lightly ground for X-ray powder diffraction.

\subsection{Methods}

\subsubsection{SEM/EDS}

Transversely and longitudinally fractured wood samples, or the glass cover slip with dried extracted crystals, were attached to an aluminum substrate using carbon conducting putty. The samples were examined uncoated in a Phenom Pharos Desktop SEM (Thermo Scientific, Waltham, MA, USA) at $15 \mathrm{kV}$ using a back scattered electron detector. The elemental compositions of the crystals were also analyzed using an attached EDS elemental detector.

\subsubsection{FTIR}

About 500 micrograms was lightly ground in an agate mortar and pestle and then mixed with 2-3 mg of spectro-grade pure KBr. The mixture was pressed into a 5-mm pellet using a Pike hand press (Pike Technologies, Fitchburg, WI, USA). The infrared spectrum of the transparent pellet was obtained using a Nicolet iS5 spectrometer (Thermo Scientific) at $4 \mathrm{~cm}^{-1}$ resolution in the range of 4000 to $400 \mathrm{~cm}^{-1}$.

\subsubsection{Raman Spectroscopy}

Micro-Raman spectra were collected by using a LabRAM HR Evolution (Horiba Scientific, Kyoto, Japan), a confocal Raman spectrophotometer, which is based on an upright modular microscope BXFM (Olympus, Tokyo, Japan). The spectrograph has a focal length of $800 \mathrm{~mm}$. The spatial resolution of the microscope at $600 \mathrm{~nm}$ is roughly $300 \mathrm{~nm}$.

A $100 \times$ objective MPlanFL, NA 0.9 (Olympus, Tokyo, Japan) was used. Laser excitation was chosen from three sources $(532 \mathrm{~nm}, 633 \mathrm{~nm}$ or $785 \mathrm{~nm}$ ). Dispersive gratings (600 or $1800 \mathrm{gr} / \mathrm{mm}$ ) were used, and exposure and averaging conditions were chosen in order to achieve the best spectral signal to noise ratio (SNR). In order to measure the Raman spectra of the fresh tree samples a crystal was located using the imaging power of the microscope and the measurement was performed using a $785 \mathrm{~nm}$ laser for reduction of fluorescence from the sample. The extracted crystals were also located under the microscope, and the laser was focused on them. For the standard samples, crystal grains were chosen from the powders. The spectra were subjected to polynomial background removal as is common in the field.

\subsubsection{X-ray Powder Diffraction (XRD)}

The measurements were carried out in reflection geometry using a TTRAX III (Rigaku, Tokyo, Japan) diffractometer equipped with a rotating $\mathrm{Cu}$ anode operating at $50 \mathrm{kV}$ and $200 \mathrm{~mA}$ and with a scintillation detector aligned at the diffracted beam after a bent graphite monochrometer. $2 \theta / \theta$ scans were performed at specular conditions in Bragg-Brentano mode with variable slits and scanned with step size of 0.02 degrees and scan speed of 1 degree per minute. Phase analysis was made using the Jade Pro software (Materials Data, Inc., Livermore, CA, USA) and PDF-4+ 2020 database (ICDD).

\section{Results}

The wood and bark from thin (1-cm diameter) branches were fractured longitudinally and transversely and then examined in a scanning electron microscope (SEM). Figure 2 shows the presence of euhedral crystals about 5-15 microns in cross section located in vessels belonging to the ray cells of the wood. Fractured wood specimens exposed to 
deionized water for 10 min contained no crystals. The crystals are, therefore, soluble in water. We also examined the wood of a Tamarix growing on the banks of the Jordan River (in the north of Israel) with its roots partially in the fresh water itself. SEM showed that similar crystals were observed in the same cells of this Tamarix tree.

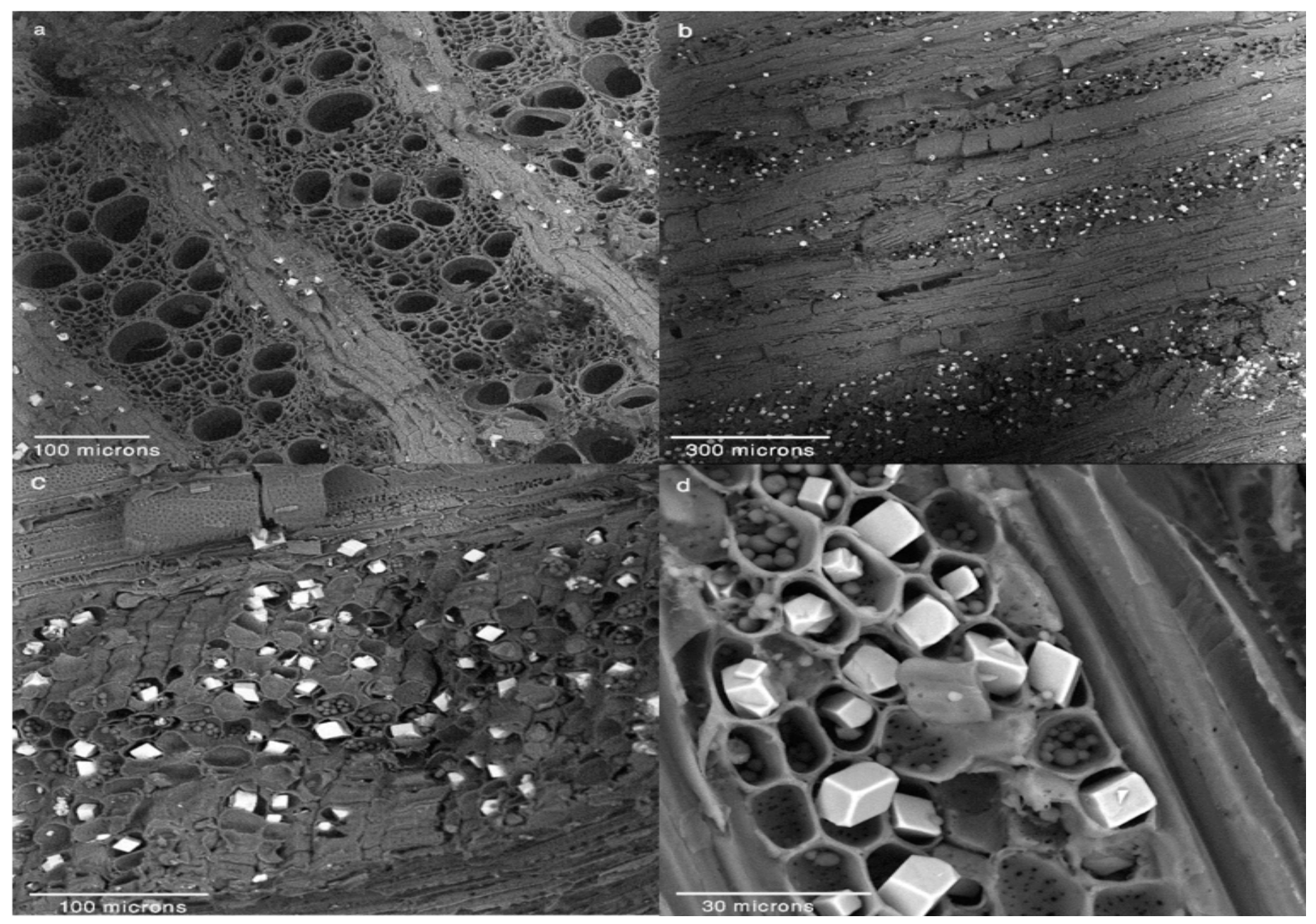

Figure 2. SEM images of the crystals in the Tamarix ray cells. (a): Transverse section. (b-d): Longitudinal sections at different magnifications.

EDS point analyses of the crystals showed that the major elements comprise approximately equal amounts of calcium and sulfur in atom percent, together with large amounts of carbon. Small amounts of sodium and potassium are also present. As the carbon and possibly the $\mathrm{Na}$ and $\mathrm{K}$ could come from the surrounding organic tissue, the crystals were extracted in ethanol and most of the associated organic material was removed by passing the suspension through a 21-micron mesh fabric. The EDS analyses of the filtered crystals did not contain $\mathrm{C}$, but still contained small but significant amounts of $\mathrm{Na}$ and $\mathrm{K}$, as well as trace amounts of Si (less than 1.0 atom percent). As Si was not present in the analyses of the crystals in the wood, we assume that the $\mathrm{Si}$ is derived from the glass substrate. The average stoichiometry of 13 extracted crystals analyzed by EDS is $(\mathrm{Ca}, \mathrm{Na}, \mathrm{K})_{1.1} \mathrm{~S}_{1.0}$. The average percent of $\mathrm{Na}$ and $\mathrm{K}$ in relation to the total cation content is 18 atom percent, and the range is from 9.9 to 29.5 atom percent. Some of the $\mathrm{Na}$ and $\mathrm{K}$ may not be included in the crystal lattice.

FTIR spectra of freshly collected and ground wood of the T. aphylla growing in the central Negev (Israel) all contain a doublet at $657 \mathrm{~cm}^{-1}$ and $600 \mathrm{~cm}^{-1}$ (Figure 3), which is consistent with the presence of calcium sulfate hemihydrate (spectrum b in Figure 3). Figure 3 also shows standards of the three common forms of calcium sulfate, namely gyp- 
sum $\left(\mathrm{CaSO}_{4} \cdot 2 \mathrm{H}_{2} \mathrm{O}\right)$, anhydrite $\left(\mathrm{CaSO}_{4}\right)$ and calcium sulfate hemihydrate $\left(\mathrm{CaSO}_{4} \cdot 0.5 \mathrm{H}_{2} \mathrm{O}\right)$, also known as bassanite or Plaster of Paris. The FTIR spectrum of Tamarix sp. wood collected fresh and stored dry at room temperature for 25 years, also contained the two peaks at 657 and $600 \mathrm{~cm}^{-1}$ (spectrum not shown).

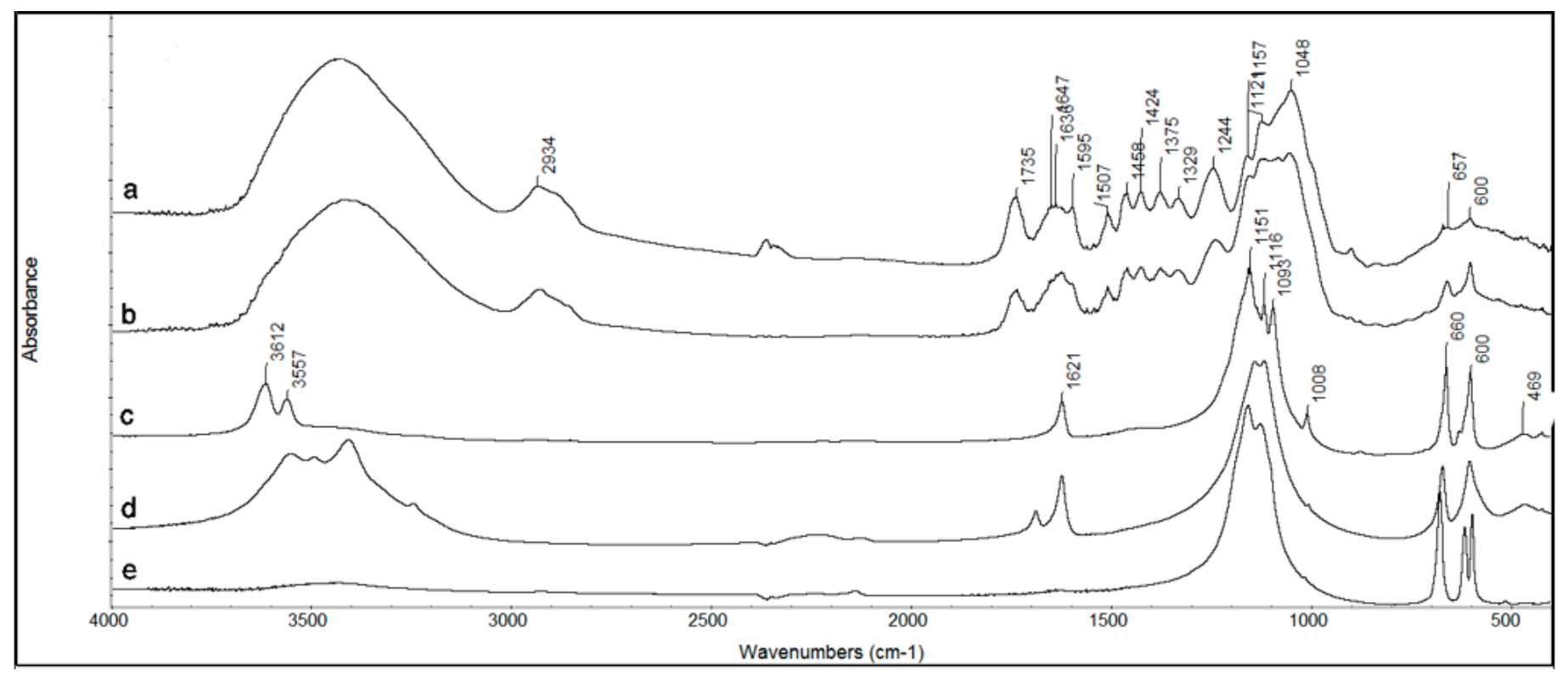

Figure 3. (a) FTIR spectrum of wood from T. aphylla growing in Nahal Aqev showing the presence of two peaks at $657 \mathrm{~cm}^{-1}$ and $600 \mathrm{~cm}^{-1}$, which are indicative of the presence of calcium sulfate hemihydrate. All the other peaks are mainly from cellulose and lignin. (b) Spectrum of the extracted crystals showing more clearly the $657 \mathrm{~cm}^{-1}$ and $600 \mathrm{~cm}^{-1}$ peaks, in addition to peaks of mainly cellulose and lignin. (c) Spectrum of standard calcium sulfate hemihydrate showing the two peaks at $660 \mathrm{~cm}^{-1}$ and $600 \mathrm{~cm}^{-1}$. (d) Spectrum of standard gypsum. (e) Spectrum of standard anhydrite.

We used the micro-Raman to obtain spectra directly from the crystals exposed at the surface of a freshly fractured piece of Tamarix wood, as well as crystals extracted from the wood in ethanol and then placed on a glass microscope slide. Figure 4 shows the Raman spectra of the crystals in the wood and after extraction, as well as the spectra of gypsum, anhydrite and calcium sulfate hemihydrate. The crystals are clearly composed of calcium sulfate hemihydrate.

The presence of around 20 atom percent $\mathrm{Na}$ and $\mathrm{K}$ of the total cations in the crystals, raised the question as to whether the crystals are composed of calcium sulfate hemihydrate or possibly the very rare mineral called omongwaite, $\left(\mathrm{Na}_{2} \mathrm{Ca}_{5}\left(\mathrm{SO}_{4}\right)_{6} \cdot 3 \mathrm{H}_{2} \mathrm{O}\right)$; a mineral from recent salt lake deposits in Namibia [17] or another member of this family. We, therefore, dried an aliquot of crystals extracted from around $200 \mathrm{mg}$ of the T. aphylla wood examined above, and obtained a powder X-ray diffraction pattern (Figure 5). This pattern confirms that the crystals are composed of calcium sulfate hemihydrate (bassanite). The baseline rise is probably from the remnants of the wood still present in the sample, although we cannot exclude the possibility that some of the mineral is in a disordered state. 


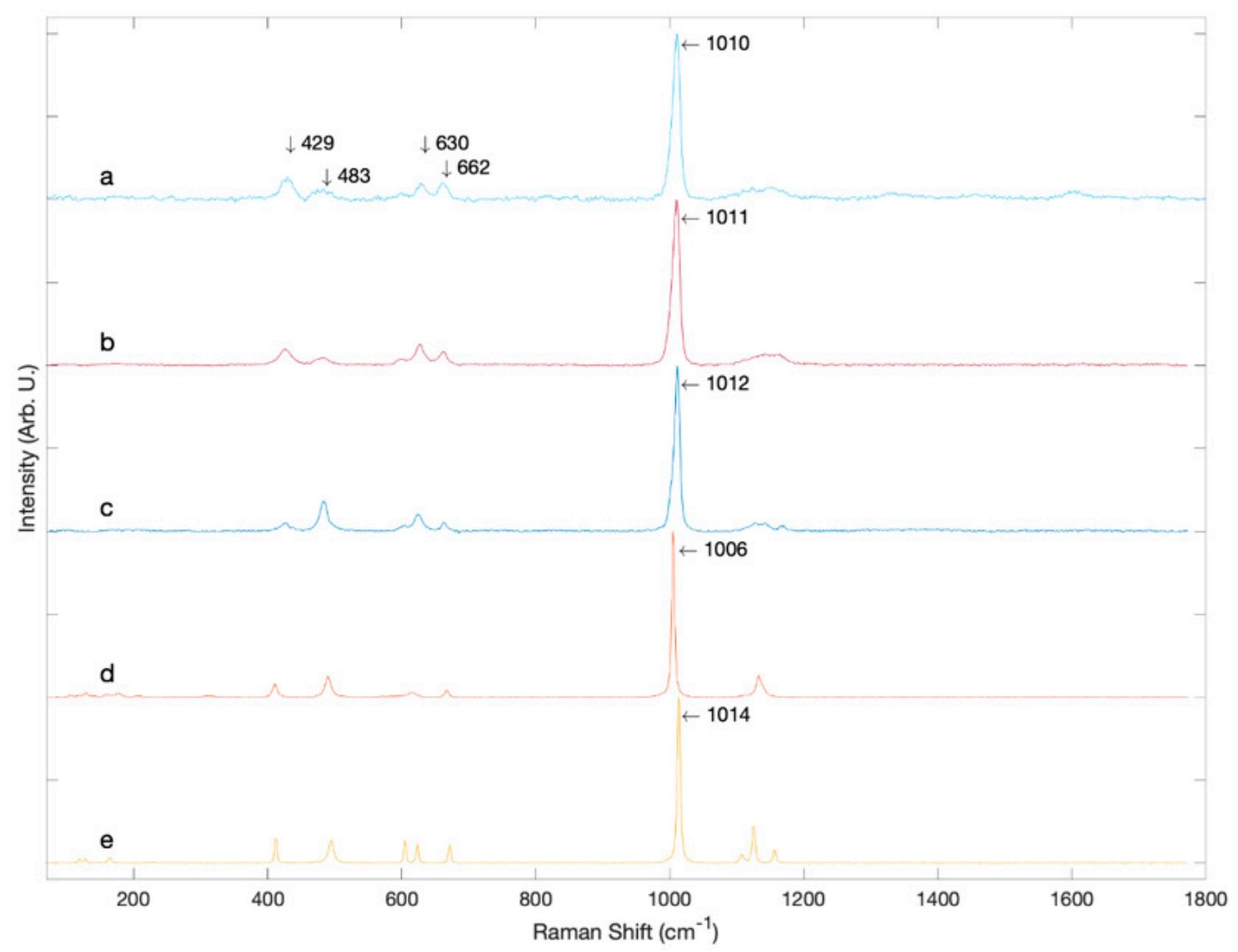

Figure 4. (a) Raman spectrum of wood from T. aphylla growing in Nahal Aqev showing the presence of calcium sulfate hemihydrate. (b) Spectrum of the filter-extracted crystals. (c). Spectrum of standard calcium sulfate hemihydrate. (d) Spectrum of standard gypsum. (e) Spectrum of standard anhydrite. The peaks in spectra $(\mathbf{a}-\mathbf{c})$ are at very similar wavenumbers.

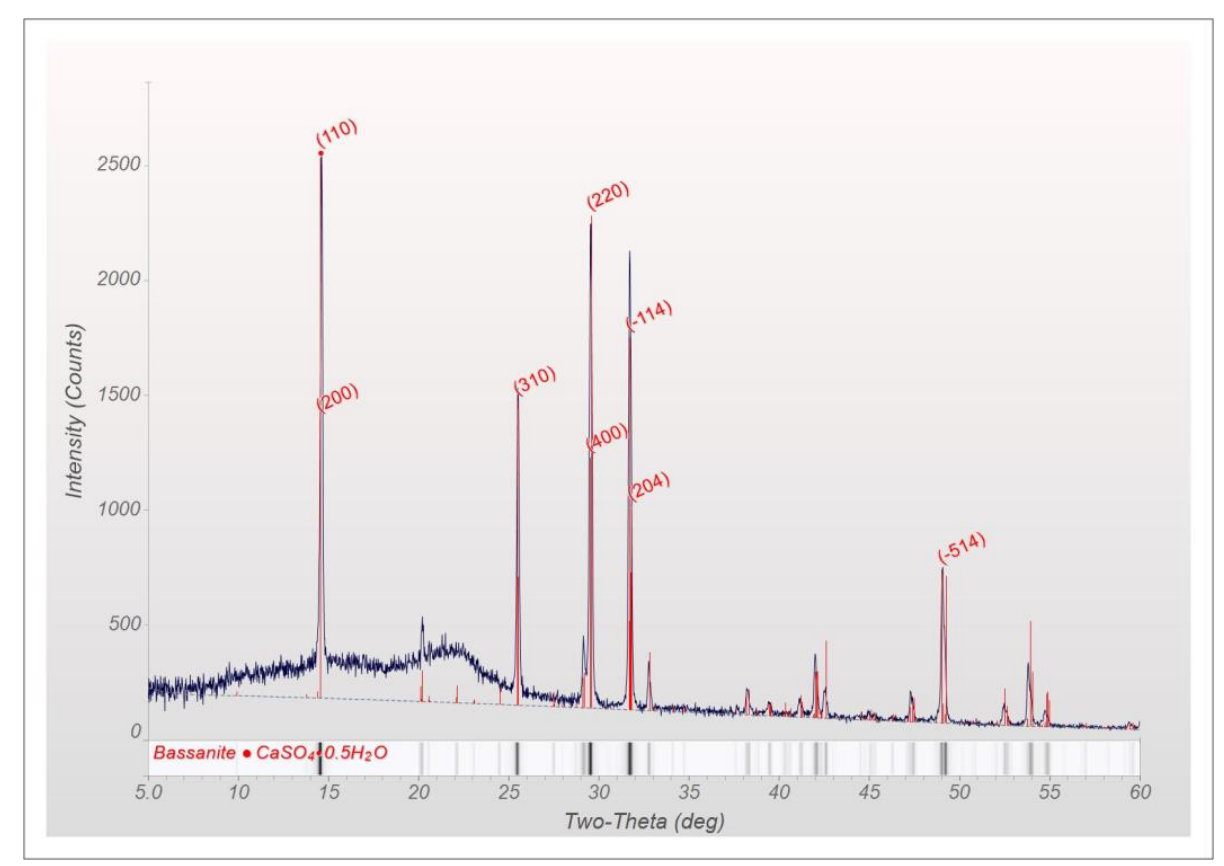

Figure 5. X-ray powder diffraction pattern of a dried aliquot of crystals extracted from approximately $200 \mathrm{mg}$ of $T$. aphylla wood. The main peaks of bassanite $\left(\mathrm{CaSO}_{4} \cdot 0.5 \mathrm{H}_{2} \mathrm{O}, \mathrm{ICDD} 98-000-0108\right)$ indicated in the figure by Miller indices $(h k l)$ have the following values of d-spacing: $d_{200}=6.016 \AA$; $d_{110}=6.003 \AA ; d_{310}=3.471 \AA ; d_{-114}=2.804 \AA ; d_{204}=2.798 \AA ; d_{-514}=1.851 \AA$. 


\section{Discussion}

Here, we show that the crystals that are present in the wood of the Tamarix aphylla are composed of the mineral calcium sulfate hemihydrate (bassanite). We emphasize that both FTIR and Raman spectroscopy analyses were also carried out directly on crystals in the wood itself, without the need for extraction, and by doing so, we exclude the possibility that the mineralogy was altered during extraction. These crystals are located in the ray cells of the Tamarix wood. Calcium sulfate hemihydrate crystals were also observed in the wood of a Tamarix sp. growing on the banks of the Jordan River in the north of Israel with some of its roots in the fresh water. Thus, clearly the formation of these crystals is not due to the tree growing in an arid environment, and crystal formation may, therefore, be genetically controlled.

Calcium sulfate hemihydrate has been reported from the wood of the tree Salvadora persica which is used as a "natural toothbrush" in many different countries [18]. The crystals are very similar in both size and shape to the crystals found in T. aphylla. For more information on the natural occurrence of geogenic calcium sulfate hemihydrate (bassanite) see Dogan et al. [18].

Biogenic calcium sulfate hemihydrate crystals have also been reported in the gravity sensors of the medusa (jellyfish) Periphylla periphylla (Scyphozoa, Coronatae) [19]. These crystals are much larger than the crystals in the wood and are elongated. They also express smooth crystal faces.

The mechanism of formation of the biogenic calcium sulfate hemihydrate in wood and the medusa is puzzling, as this mineral cannot be precipitated from water under normal conditions and the temperature required to dehydrate gypsum to the hemihydrate is around $100{ }^{\circ} \mathrm{C}$ [19]. Furthermore, this mineral is highly soluble, and even a brief exposure to water of a freshly fractured piece of Tamarix wood, resulted in the crystals dissolving. If they were protected by a thin coat of organic material in vivo, this would not be expected to occur. Apparently, water is prevented somehow from entering into the vacuoles in which the crystals reside in the Tamarix wood. We do not know the function(s) of the calcium sulfate hemihydrate crystals in the Tamarix.

Tamarix trees are common in arid environments and their wood was most likely used as fuel in the past. This has been documented for a site in the Negev, Israel [9]. During the burning process, the calcium sulfate hemihydrate transforms into anhydrite, which then hydrates and forms gypsum [9]. Thus, the presence of gypsum in archaeological sites in arid regions may well indicate that Tamarix was used as a fuel, especially if the gypsum is associated with other materials that were exposed to high temperatures, such as clay minerals and bone.

\section{Conclusions}

Here, we use SEM, infrared spectroscopy, Raman spectroscopy and X-ray powder diffraction to show that the wood of Tamarix aphylla contains crystals of calcium sulfate hemihydrate (bassanite) in its ray cells. As similar crystals are present in the wood of a Tamarix growing in northern Israel, on the banks of the Jordan River, we conclude the crystal formation may be a genetically controlled process and not a function of the arid environment.

Author Contributions: I.P. was responsible for the Raman spectroscopy, Y.F. for the X-ray diffraction and A.K. and S.W. for the SEM and EDS analyses. All the authors participated in the analysis of the results and the writing of the paper. All authors have read and agreed to the published version of the manuscript.

Funding: This research received no external funding.

Acknowledgments: We thank Valentina Caracuta for identifying the species of Tamarix that we are analyzing and that the crystals are in the ray cells. I.P. is the incumbent of the Sharon Zuckerman research fellow chair. 
Conflicts of Interest: The authors declare no conflict of interest.

\section{References}

1. Scurfield, G.; Michell, A.J.; Silva, S.R. Crystals in woody stems. Bot. J. Linn. Soc. 1973, 66, 277-289. [CrossRef]

2. Arnott, H.J.; Pautard, F.G.E. Calcification in plants. In Biological Calcification: Cellular and Molecular Aspects; Schraer, H., Ed.; Appleton-Century-Crofts: New York, NY, USA, 1970; pp. 375-441.

3. Gal, A.; Brumfeld, V.; Weiner, S.; Addadi, L.; Oron, D. Certain biominerals in leaves function as light scatterers. Adv. Opt. Mat. 2012, 24, 77-83. [CrossRef] [PubMed]

4. Scurfield, G.; Anderson, C.A.; Segnit, E.R. Silica in woody stems. Aust. J. Bot. 1974, 22, 211-229. [CrossRef]

5. Schiegl, S.; Lev-Yadun, S.; Bar-Yosef, S.; El Goresy, A.; Weiner, S. Siliceous aggregates from prehistoric wood ash: A major component of sediments in Kebara and Hayonim caves (Israel). Isr. J. Earth Sci. 1994, 43, 267-278.

6. Pritchard, S.G.; Prior, S.A.; Rogers, H.H.; Peterson, C.M. Calcium sulfate deposits associated with needle substamoatal cavities of container-grown longleaf pine (Pinus palustris) seedlings. Int. J. Plant Sci. 2000, 161, 917-923. [CrossRef]

7. He, H.; Bleby, T.M.; Veneklaas, E.J.; Lambers, H.; Kuo, J. Morphologies and elemental compositions of calcium crystals in phyllodes and branchlets of Acacia robeorum (Leguminosae: Mimosoideae). Ann. Bot. 2012, 109, 887-896. [CrossRef] [PubMed]

8. Tsartsidou, G.; Lev-Yadun, S.; Albert, R.-M.; Miller-Rosen, A.; Efstratiou, N.; Weiner, S. The phytolith archaeological record: Strengths and weaknesses evaluated based on a quantitative modern reference collection from Greece. J. Archaeol. Sci. 2007, 34 , 1262-1275. [CrossRef]

9. Shahack-Gross, R.; Finkelstein, I. Subsistence practices in an arid environment: A geoarchaeological investigation in an Iron Age site, the Negev Highlands, Israel. J. Archaeol. Sci. 2008, 35, 965-982. [CrossRef]

10. Weiner, S. Microarchaeology: Beyond the Visible Archaeological Record; Cambridge University Press: New York, NY, USA, 2010.

11. Pobequin, T. Les oxalates de calcium chez quelques Angiosperms. Ann. Sci. Nat. Bot. 1943, 4, 1-95.

12. Ozawa, T. A new method of analyzing thermogravimetric data. Bull. Chem. Soc. Jpn. 1965, 38, 1881-1886. [CrossRef]

13. Storey, R.; Thomson, W.W. An X-ray microanalysis study of the salt glands and intracellular calcium crystals of Tamarix. Ann. Bot. 1994, 73, 307-313. [CrossRef]

14. Shuyskaya, E.V.; Rakhamkulova, Z.F.; Lebedeva, M.P.; Kolesnikov, A.V.; Safarova, A.; Borisochkina, T.I.; Toderich, K.N. Different mechanisms of ion homeostasis are dominant in the recretohalophyte Tamarix ramosissima under different soil salinity. Acta Physiol. Plant 2017, 39, 81-93. [CrossRef]

15. Chew, M.K. The monstering of tamarisk: How scientists made a plant into a problem. J. Hist. Biol. 2009, 42, 231-266. [CrossRef] [PubMed]

16. Waly, W. Wood anatomical characters of the Egyptian Tamarix L. species and its taxonomic significance. Taeckholmia 1999, 19, 115-125. [CrossRef]

17. Mees, F.; Hatert, F.; Rowe, R. Omongwaite, $\mathrm{Na}_{2} \mathrm{Ca}_{5}\left(\mathrm{SO}_{4}\right)_{6} \cdot 3 \mathrm{H}_{2} \mathrm{O}$, a new mineral from recent salt lake deposits, Namibia. Mineral. Mag. 2008, 72, 1307-1318. [CrossRef]

18. Dogan, A.U.; Dogan, M.; Chan, C.N.; Wurster, D.E. Bassanite from Salvadora persica: A new evaporitic biomineral. Carbonates Evaporites 2005, 20, 2-7. [CrossRef]

19. Tiemann, H.; Sötje, I.; Jarms, G.; Paulmann, C.; Epple, M.; Hasse, B. Calcium sulfate hemihydrate in statoliths of deep-sea medusae. J. Chem. Soc. Dalton Trans. 2002, 1266-1268. [CrossRef] 